\title{
Transgenic Rice Expressing Amyloid $\beta$-peptide for Oral Immunization
}

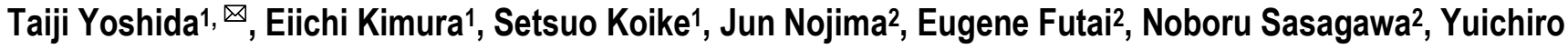 Watanabe2, and Shoichi Ishiura²}

1. National Agricultural Research Center for Tohoku Region, National Agriculture and Food Research Organization, Iwate, Japan

2. Department of Life Sciences, Graduate School of Arts and Sciences, The University of Tokyo, Tokyo, Japan

$\triangle$ Corresponding author: T. Yoshida, National Agricultural Research Center for Tohoku Region, National Agriculture and Food Research Organization, 4 Akahira, Shimo-kuriyagawa, Morioka, Iwate 020-0198, Japan. Tel: +81 19643 3528; Fax: +81 19 643 3698; E-mail address: yoshidat@affrc.go.jp

(C) Ivyspring International Publisher. This is an open-access article distributed under the terms of the Creative Commons License (http://creativecommons.org/ licenses/by-nc-nd/3.0/). Reproduction is permitted for personal, noncommercial use, provided that the article is in whole, unmodified, and properly cited.

Received: 2010.12.11; Accepted: 2011.03.22; Published: 2011.03.25

\begin{abstract}
Various vaccine therapies for Alzheimer's disease (AD) have been investigated. Here we report transgenic rice expressing amyloid $\beta$-peptide $(A \beta)$. The $A \beta 42$ gene fused with a green fluorescent protein gene was introduced into rice using the Agrobacterium method. When transgenic brown rice expressing $A \beta$ was orally administered to mice, serum anti- $A \beta$ antibody titers were elevated. The same results were observed when mice were fed boiled, transgenic brown rice. The results indicate that an edible vaccine against $A D$ using rice may be feasible. $A$ vaccine derived from rice would be far cheaper than existing medical vaccines.
\end{abstract}

Key words: Alzheimer's disease, amyloid $\beta$-peptide, edible vaccine, Oryza sativa, brown rice

\section{Introduction}

Alzheimer's disease (AD) causes cognitive impairment and while symptomatic therapies such as donepezil hydrochloride are available, no existing therapeutic medication offers complete recovery from AD. The development of new AD therapies would lessen the social and economic burden of the disease.

The onset of $\mathrm{AD}$ is thought to be due to amyloid $\beta$-peptide $(\mathrm{A} \beta)$ deposition in the cerebral cortex $[1,2]$. As $A \beta$ is a protein, vaccines for $A D$ are potential means of therapy or prevention [3-5]. In trials using mouse models of $A D$, injection with $A \beta$ as an antigen reduced the level of $A \beta$ accumulation in the brain notably, reduced memory defects and improved behavioral disorders [6,7]. A phase I clinical trial of vaccine therapy by intramuscular injection of $A \beta$ was completed without problems but the phase II clinical trial was terminated because some patients developed meningoencephalitis [8]. In a 6-year follow-up of pa- tients in the trial of $\mathrm{AD}$ immunization [9], cortical $\mathrm{A} \beta$ loads were lower in immunized patients compared to the control group. Patients with higher antibody responses had more extensive $A \beta$ removal. However, this study did not find survival or time to severe dementia improved in immunized patients versus the control group.

A vaccine therapy with no side effects is needed. Oral or other mucosal vaccinations appear to have fewer side effects than vaccines administered by injection $[10,11]$. A potential method of oral vaccination is to express a target protein in an edible plant. Increased serum anti-A $\beta$ antibody titer and suppressed $A \beta$ deposition in the brain were observed when green pepper or potato containing $A \beta$ was fed to a mouse model of AD [11,12,13,14]. Edible vaccine might also be produced in genetically modified food plants such as rice or soybeans that accumulate $A \beta$ in seeds. Ce- 
real seeds are better suited for edible vaccines than fruit or vegetables as many have high protein content and can be stored for long periods at room temperature.

In the present study, we introduced the $A \beta$ gene conjugated with green fluorescent protein (GFP) into rice, and orally administered modified rice to mice in order to investigate the effects of $A \beta$ on serum anti-A $\beta$ antibody titer.

\section{Materials and Methods}

\section{Plant materials}

Oryza sativa L. cultivar Hayayuki (Japonica rice in Japan) was used in this study. Mature seeds (brown rice) were sterilized in $70 \%$ ethanol for $10 \mathrm{~s}$ and $1 \%$ sodium hypochlorite for $15 \mathrm{~min}$, and rinsed in sterile distilled water. Seeds were placed on N6D medium $[15,16]$ for callus formation. Cultures were incubated at $25^{\circ} \mathrm{C}$ under a $16-\mathrm{h}$ photoperiod using cool-white fluorescent light at $40 \mu \mathrm{mol} / \mathrm{m}^{2} / \mathrm{s}$. Calli were isolated from seed scutella 10-30 days later, and used for $A \beta$ gene induction.

\section{Plasmid construction}

The nucleoside sequence coding $A \beta 42$ was amplified by PCR using primers $A \beta-5^{\prime}-X h o I$ (5'-GAAGTCTCGAGTGATGCAGAAT-3') and A $\beta$-3'-HindIII (5'-GAACGAAGCTTTTACGCTATGA CA-3'). The gene for the APP695 protein was used as a template. The product was digested with XhoI and HindIII, and inserted into pEGFP-C2 (Clontech) at restriction sites resulting in $\mathrm{PEGFP}-\mathrm{A} \beta-\mathrm{C} 2$.

The nucleoside sequence coding sGFP(S65T) [17] was amplified by PCR using primers sGFP-5'-AgeI (5'-ATACCGGTCGCCACCATGGTGAGCAAGGGC GAG-3') and sGFP-3'-BglII (5'-TCAGATCTGAGT CCGGCCGGACTTGTACAGCTCGTCCAA-3'). The product was digested with AgeI and BglII, and ligated to the $\mathrm{pEGFP}-\mathrm{A} \beta-\mathrm{C} 2$ at the restriction sites to produce psGFP-A $\beta-C 2$. The GFP-A $\beta$ fused gene was produced by amplifying psGFP-A $\beta-C 2$ by PCR using primers sGFP-5'-XbaI (5'-TTTCTAGAATGGTGAGCAAGG GCGAGGAG-3 $\left.{ }^{\prime}\right)$ and A $\beta$ - $3^{\prime}$-SacII $\left(5^{\prime}\right.$-TTGAGCT CGACTGCAGAATTCGAAGCTT-3'), followed by digestion with $\mathrm{XbaI}$ and SacII.

The binary vector pIG121-Hm [18] was digested with $\mathrm{XbaI}$ and SacII to remove the Intron-Gus gene. The GFP-A $\beta$ fused gene was then ligated to pIG121-Hm to produce pIG121-Hm (sGFP+A $\beta)$.

The binary vector pIG121-Hm (sGFP+A $\beta$ ) was electroporated into Agrobacterium tumefaciens strain EHA101 using an Escherichia coli pulser (Bio-Rad). Transformants EHA101 (pIG121-Hm (sGFP+A $\beta)$ ) were selected on LB medium containing $50 \mathrm{mg} / \mathrm{L}$ kanamycin, $50 \mathrm{mg} / \mathrm{L}$ hygromycin $\mathrm{B}$ and $1.2 \%$ Bacto-agar.

\section{Transformation}

EHA101 (pIG121-Hm (sGFP+A $\beta)$ ) was grown overnight on LB medium with $50 \mathrm{mg} / \mathrm{L}$ kanamycin, $50 \mathrm{mg} / \mathrm{L}$ hygromycin, and $1.2 \%$ Bacto-agar at $25^{\circ} \mathrm{C}$. Bacteria were suspended in AAM medium [19]. Rice calli were immersed in AAM medium containing the bacteria for $15 \mathrm{~min}$.

Calli were transferred to N6D medium, modified to $\mathrm{pH} 5.2$, containing $100 \mu \mathrm{M}$ acetosyringone, and incubated in the dark at $22^{\circ} \mathrm{C}$ for 3 days. After co-cultivation, calli were washed with the medium (N6 salts, N6 vitamins, 2 mg/L 2,4-D, 30 g/L sucrose, $400 \mathrm{mg} / \mathrm{L}$ carbenicillin, $\mathrm{pH}$ 5.8).

Washed calli were cultured on selective media (N6D medium with $50 \mathrm{mg} / \mathrm{L}$ hygromycin B and 400 $\mathrm{mg} / \mathrm{L}$ carbenicillin) at $25^{\circ} \mathrm{C}$ under a $16-\mathrm{h}$ photoperiod. White or yellow calli were transferred every 10 days to the same medium.

Calli were transferred to plant regeneration medium [20] modified with $100 \mathrm{mg} / \mathrm{L}$ carbenicillin. Cultures were incubated at $25^{\circ} \mathrm{C}$ under a 16 -h photoperiod. Calli with green spots or plantlets were transferred every 5-10 days, until the plantlets grew to more than $1 \mathrm{~cm}$ in height. Plantlets were transferred into hormone-free MS medium, and fully grown plantlets were planted in soil.

\section{Southern blot analysis}

Extracted leaf DNA was digested with XbaI. Electrophoresis was performed on $1.0 \%$ agarose gels, and DNAs were blotted onto a Hybond-N+ membrane (GE Healthcare) and were subjected to Southern hybridization. GFP sequence containing the whole coding region was used as a probe. Probe labeling and southern hybridization procedures were performed using the AlkPhos direct labeling and detection system with CDP-Star (GE Healthcare).

\section{Quantification of expression levels in seeds}

Frozen seeds were crushed. Total protein in one seed (approximately $20 \mathrm{mg}$ ) was extracted for $1 \mathrm{~h}$ with $400 \mu \mathrm{L}$ protein extraction buffer $(20 \mathrm{mM}$ Tris- $\mathrm{HCl}(\mathrm{pH}$ 6.5), $8 \mathrm{M}$ urea, 5\% 2-mercaptoethanol, $20 \%$ glycerol, $4 \%$ SDS), and was centrifuged for $10 \mathrm{~min}$ at $20,000 \times \mathrm{g}$. Three microliters of each supernatant was applied to Tris-Tricine SDS-PAGE (12\% T, 3\% C) together with $\mathrm{A} \beta$ (human, 1-42) (Peptide Institute) as standards, and the separated protein were transferred to a Hybond-P PVDF membrane (GE Healthcare). The membrane was first incubated in blocking buffer (5\% skim milk, T-PBS), and treated with anti-A $\beta$ antibody 6E10 (Sig- 
net). The GFP-A $\beta$ fusion protein bound to the membrane was detected using the HRP-conjugated secondary antibody (GE Healthcare) and the ECL plus Western blotting detection system (GE Healthcare).

\section{Mouse immunization}

The quantity of brown rice administered to each mouse was adjusted to deliver $10 \mu \mathrm{g}$ of $\mathrm{A} \beta$. Crushed brown rice was mixed with cholera toxin $\mathrm{B}$ (CTB, List Biological Laboratories) (5 $\mu \mathrm{g}$ per mouse) in PBS. C57BL/6J mice (Charles River) were divided into three groups (eight mice per group) and were orally fed with a feeding needle (non-transgenic brown rice, $A \beta$-containing brown rice ( $A \beta$ rice), or boiled $A \beta$ rice). Mice received doses of rice once a week from 8 to 11 weeks of age. As a booster, $0.5 \mu \mathrm{g}$ of $\mathrm{A} \beta$ mixed with Freund's incomplete adjuvant was injected subcutaneously into all mice at 14 weeks of age. Blood serum was collected at $8,12,14$, and 16 weeks of age. Mice were housed at $25^{\circ} \mathrm{C}$ with a 12 -h light/dark cycle. All animal procedures were approved by the Animal Care and Use Committee of the National Agricultural Research Center for the Tohoku Region.

\section{Quantification of the anti-A $\beta$ antibody titer with ELISA}

Micro plate wells were coated with $A \beta 42$ dissolved in $0.15 \mathrm{M}$ ammonium. After washing with PBS-T, wells were blocked with blocking buffer ( $3 \%$ skim milk, PBS), and were washed. Blood serum samples were diluted 10-50 times. Anti-A $\beta$ antibody 6E10 $(1 \mathrm{mg} / \mathrm{mL})$ was diluted 10,000-160,000 times as a positive control. Each sample was applied to a well and incubated at $37^{\circ} \mathrm{C}$ for $1 \mathrm{~h}$. After washing, each well was blocked at room temperature for $30 \mathrm{~min}$ with $3 \%$ skim milk and was washed again. Wells were incubated with HRP-conjugated secondary antibody at $37^{\circ} \mathrm{C}$ for $1 \mathrm{~h}$ and were washed. Wells were incubated with a TMB kit (Pierce) at room temperature in the dark. The reaction was stopped with $2 \mathrm{M}$ sulfuric acid. Absorbance at $450 \mathrm{~nm}$ was measured with a spectrophotometer (Infinite F300, Tecan), and antibody titers were calculated $(0.1 \mu \mathrm{g} / \mathrm{mL} 6 \mathrm{E} 10=100$ units $/ \mathrm{mL}$ antibody titer).

\section{Detection of the anti-A $\beta$ antibody production by Western blot analysis}

A $\beta$ (240 ng) was applied to $12 \%$ polyacrylamide gels containing $0.1 \%$ SDS; separated proteins were transferred to a Hybond-P PVDF membrane. The membrane was first incubated in blocking buffer (ECL Advance blocking agent, GE Healthcare), and treated with serum samples (10 times dilution). Anti-A $\beta$ production was detected by HRP-conjugated secondary antibody and the ECL advance Western blotting detection kit (GE Healthcare).

\section{Results and Discussion}

Initially, the luminescence of transgenic rice expressing the EGFP-A $\beta$ fusion gene was weak. The sGFP(S65T) gene is designed for plant use and gives brighter light in the plant than the original GFP [17]. We therefore expressed sGFP instead of EGFP in rice, and the resulting transgenic rice seeds exhibited stronger luminescence with many fluorescent spots (Fig. 1A, B). Fluorescence was localized mainly in the aleurone layer of brown rice (Fig. 1C). Polished rice had a little fluorescence (Fig. 1D).

These results show that $A \beta$ accumulates in aleurone layer, and if brown rice is polished, a proportion of $A \beta$ is removed from the rice. Most rice eaten in Japan is polished, and brown (non-polished) rice must be eaten for $\mathrm{AD}$ vaccination to succeed.

The presence of the A $\beta$-GFP gene in the leaves of primary transgenic rice plants $\left(\mathrm{R}_{0}\right.$ rice plants) was investigated by PCR analysis using primers sGFP-5'-XbaI and A $\beta-3^{\prime}$-SacII (data not shown). In samples where PCR analysis indicated the presence of the $A \beta$-GFP gene, Southern blot analysis was used to confirm transformation in individual plants (Fig. 2). The $A \beta$-GFP gene was introduced into $R_{0}$ plants except line No. 32. The positive PCR result in the Line No. 32 plant may have been due to residual Agrobacterium in plant tissue.

Western blotting was used to investigate the accumulation of the $A \beta$-GFP fusion protein in $A \beta$ transgenic rice (Fig. 3). The signal intensity of the band was compared against the signal intensity of $\mathrm{A} \beta 42$ as a control, and differences were observed among lines. The highest concentration, $8 \mu \mathrm{g}$ of $\mathrm{A} \beta$ in a single grain of brown rice $(400 \mu \mathrm{g} / \mathrm{g}$ brown rice) was found in samples from line 29, compared with 18-50 $\mu \mathrm{g} A \beta$ [13] and $77 \mu \mathrm{g} A \beta$ [14] per gram of soluble protein found in potato in previous studies.

Immunogenicity of $A \beta$ rice was assessed by feeding brown $A \beta$ rice to C57BL/6J mice, from 8 to 11 weeks of age, and assessing serum anti-A $\beta$ antibody titer by ELISA (Fig. 4). At 12 weeks age, we observed a significant increase in serum anti-A $\beta$ antibody titer in mice fed boiled $A \beta$ rice; the increase was not significant in mice fed uncooked $A \beta$ rice. Anti-A $\beta$ antibody was also detected by Western blot analysis in mice fed $\mathrm{A} \beta$ rice (Fig. $4 \mathrm{~B}$ ). No increase of anti-A $\beta$ antibody titer was detected in mice at 14 weeks of age, three weeks after the last oral administration (Fig. 4C); but the anti-A $\beta$ antibody titer significantly increased again at 16 weeks of age, after a subcutaneous booster injection (Fig. 4D). 

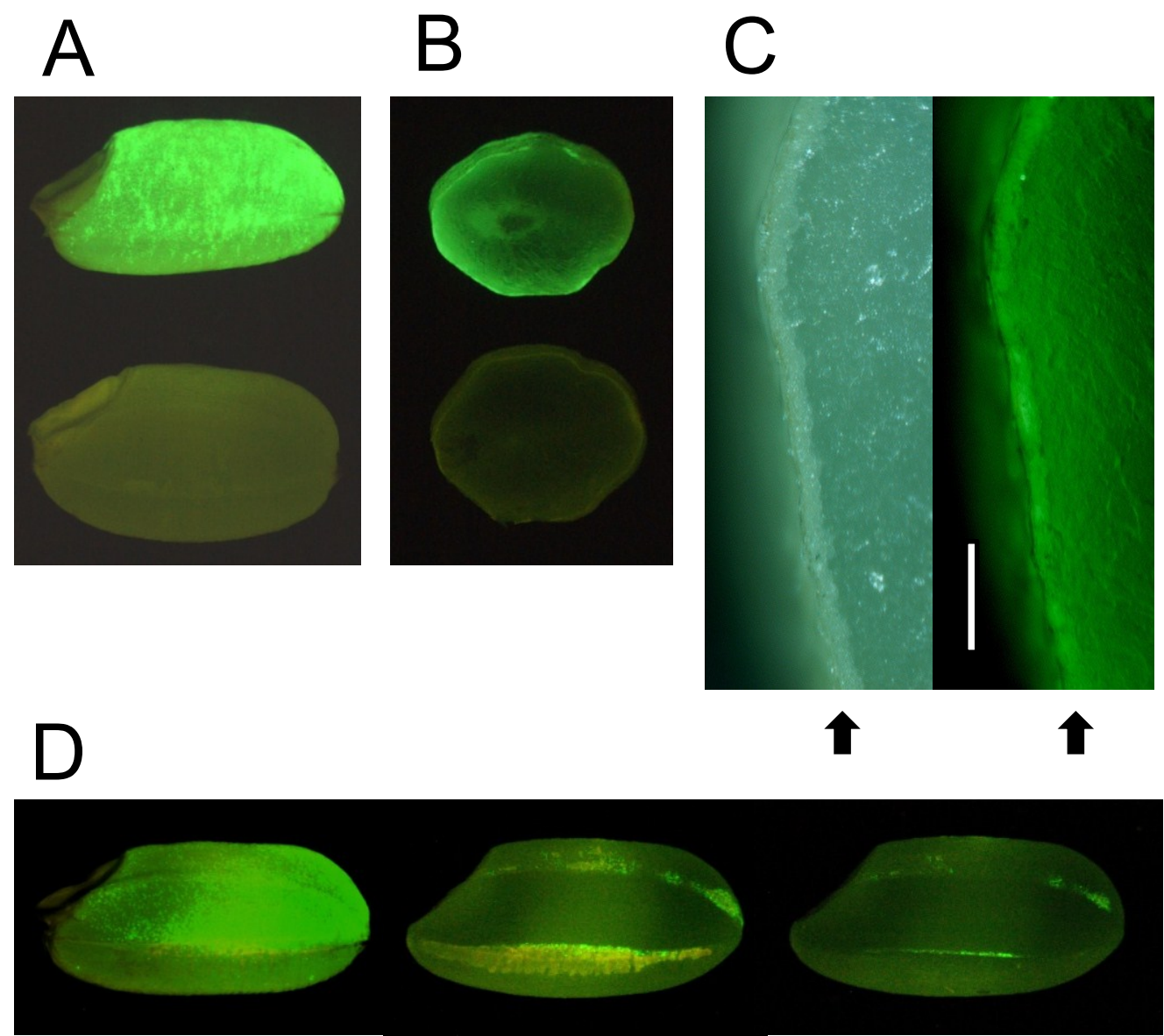

Fig. I. Detection of GFP fluorescence in seeds (brown rice). (A) Transgenic brown rice (upper seed) and non-transgenic brown rice (lower seed). (B) Transverse sections of transgenic brown rice (upper seed) and non-transgenic brown rice (lower seed). (C) Aleurone layer in transverse section of transgenic brown rice. Right panel shows fluorescence view. Bar indicates $200 \mu \mathrm{m}$. Arrows show aleurone layer. (D) Effects of polishing transgenic brown rice: non-polished rice (left seed, weight: $21.3 \mathrm{mg}$ ), the roughly polished rice (middle seed), and the polished rice (right seed, weight: $19.1 \mathrm{mg}$, rice-polishing

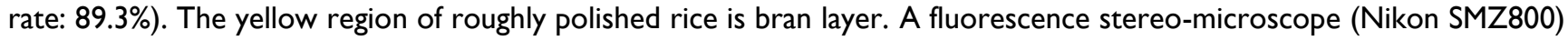
was used to observe GFP fluorescence.

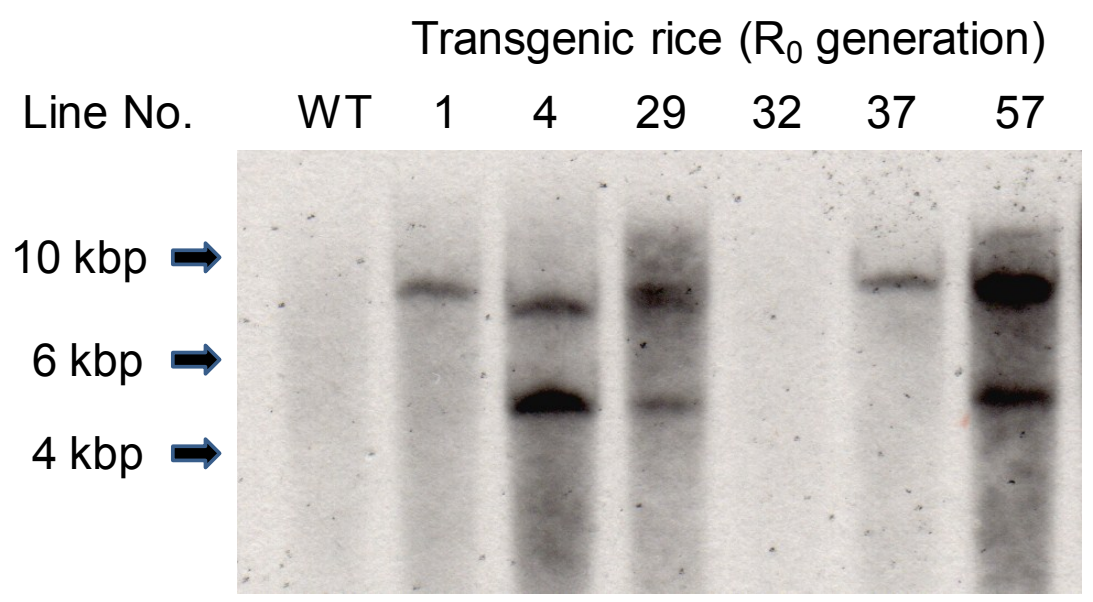

Fig. 2. Southern blot analysis of Xba l-digested total DNA probed for GFP-specific genes. WT, non-transgenic rice plant: $R_{0}$, primary transgenic rice plant. 


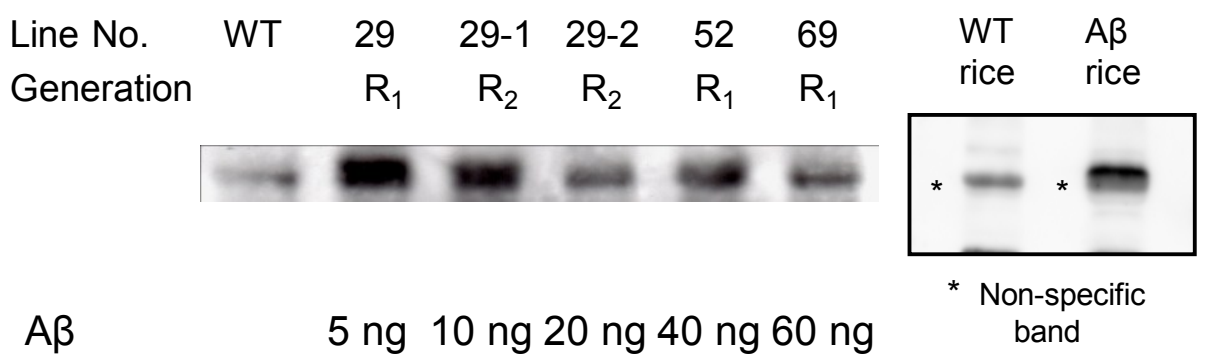

Fig. 3. Determination of $A \beta 42$ expression levels. Brown rice samples were subjected to SDS-PAGE with $A \beta 42$ at increasing concentration $(5,10,20,40$ and $60 \mathrm{ng})$. Approximately $0.15 \mathrm{mg}$ of crushed seeds was applied to each lane. $R_{0}$ seeds $\left(R_{1}\right.$ generation) and $R_{1}$ seeds $\left(R_{2}\right.$ generation) were used. WT; non-transgenic rice; $R_{1}, R_{0}$ progeny; $R_{2}, R_{1}$ progeny. Faint band in WT is non-specific band just below $A \beta 42$ band.
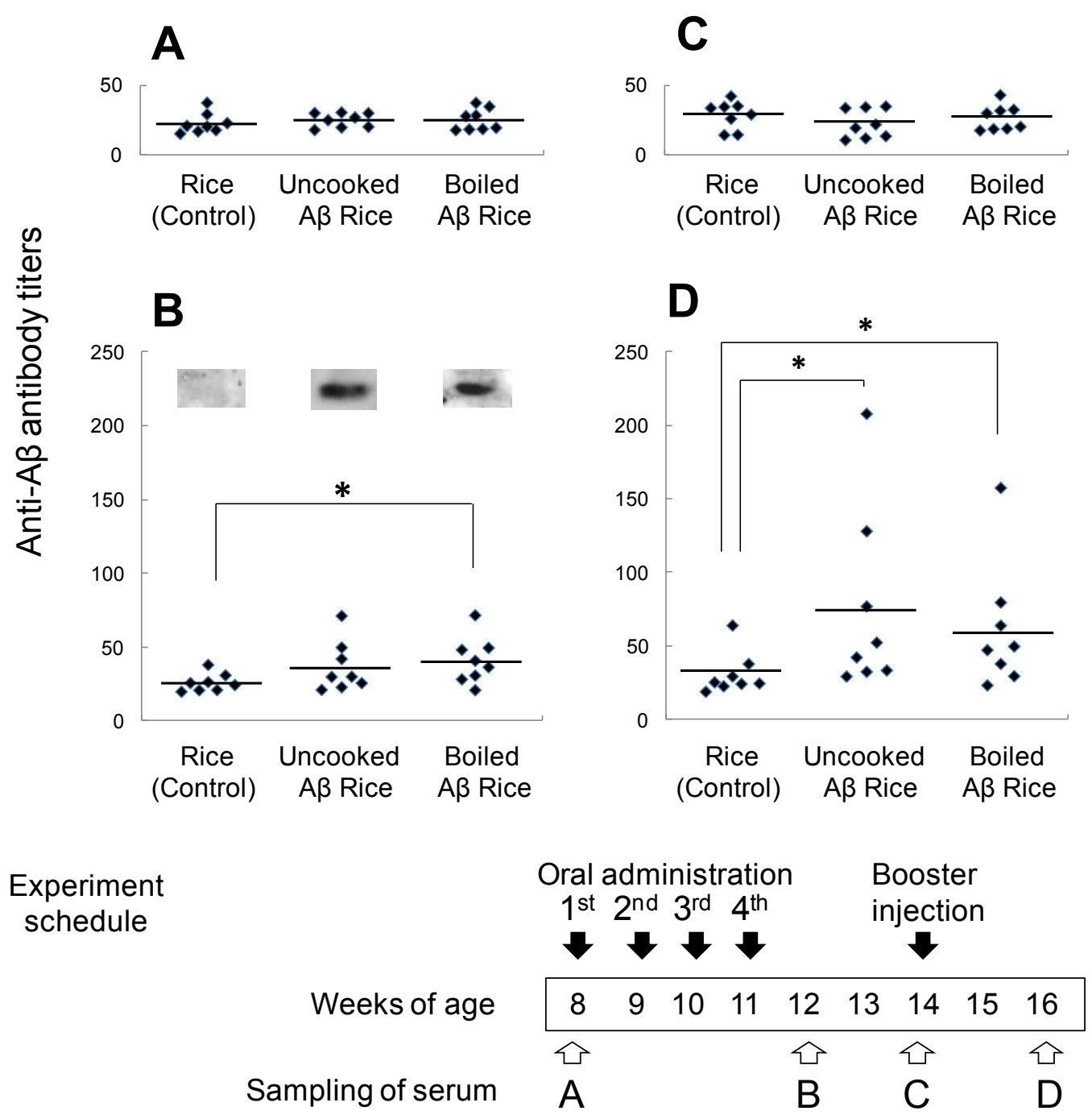

Fig. 4. Titers of antibodies against $A \beta$ in serum from 8-week-old mice before immunization (A), 12-week-old and 14-week-old mice after immunization (B, $C$, each), and 16-week-old mice after booster injection (D). Anti-A $\beta$ antibody titers for each mouse are shown. Horizontal lines show average. $\mathrm{P}<0.05$ vs. control. Data were compared by $t$-test after logarithmic conversion. Antibody production evaluated by Western blot analysis (B). For each group, four serum samples with highest anti-A $\beta$ antibody titers were mixed and used for Western blot analysis. 
The increase of anti-A $\beta$ antibody titer after booster injection shows the presence of anti-A $\beta$ antibody response in mice fed uncooked $A \beta$ rice or boiled $A \beta$ rice. However, the increase in anti-A $\beta$ antibody titer at 12 weeks of age shows the booster injection was not necessary for $A \beta$ oral immunization.

In a previous study using green pepper containing $A \beta$ [11], we examined the effect on anti-A $\beta$ antibody titers of orally immunized mice and subcutaneously immunized mice over a long-term (12.5 months) trial. The increases in anti-A $\beta$ antibody titer of orally immunized mice were similar to increases in injected mice. In the present study, the increases in anti-A $\beta$ antibody titers of mice fed $A \beta$ rice were not as great as those observed in mice given a booster injection. The difference between the studies may arise from the differences in the period of antigen administration. Further, even if an antibody response is weak, $A \beta$ in mice brains may be removed by long-term immunization of the AD mouse models [21]. Taken together, we conclude that long-term oral administration of $A \beta$ rice without $A \beta$ injection can prevent and treat $\mathrm{AD}$ in mice.

In general, the immunological effect after oral-intestinal mucosal immunization tends to be weak, and this method may induce immunological tolerance. Oral immunological tolerance can be suppressed by the use of specific adjuvants. Bacterial toxin, such as CTB, is often used as an adjuvant in oral immunization of mice. Although CTB may not be highly toxic, there may be some clinical side effects. A safer adjuvant might be developed from plants that produce compounds such as saponin [22] and it may be feasible to develop adjuvant-free oral vaccine from plants. Further animal study is necessary to determine the effectiveness of adjuvant-free $\mathrm{A} \beta$ rice for $\mathrm{AD}$.

In a previous study, we developed a technique in which a plant (green pepper) was infected with a plant virus, causing $A \beta$ to accumulate within the plant [12]. Mice that were orally administered A $\beta$-containing plant tissue showed lower levels of serum IgG2a, an inflammatory Th1 immunological globulin, than mice in which the vaccine was administered by injection [11]. These results indicate that the plant-derived vaccine is safe and effective. In addition, vaccines made using plants are far safer than vaccines from animal cells or microbes as there is less danger of the vaccine being adulterated with prion proteins, pathogenic viruses, or bacterial toxins. Thus, plant-derived vaccines require less purification, and may be produced cheaply.

The rice cultivar 'Hayayuki' used in this study is an early-ripening variety that can be harvested ap- proximately 3 months after planting. Moreover, its compact form allows year-round production in a greenhouse or plant factory so that transgenic rice would be easily contained. The additional cost of contained production is likely to be justified by a high added-value product, such as a remedy for AD.

In the present study, we showed that oral administration of $A \beta$ rice to mice elevated serum Anti-A $\beta$ antibody titer. We previously found oral administration of $\mathrm{A} \beta$ green pepper to $\mathrm{Tg} 2576$ mouse models elevated serum Anti-A $\beta$ antibody titer and reduced senile plaques; and that there was an inverse correlation between anti-A $\beta$ antibody titers and soluble intracerebral $A \beta$ [11]. It is likely that accumulation of $A \beta$ in the brain can be suppressed by administering $A \beta$ rice. We plan a further experiment with AD mouse models to investigate whether oral immunization by long-term administration of $A \beta$ rice decreases senile plaques.

Rice is commonly eaten in grain form without first being pulverized. This would make it easy to control intake, as with medicines in pill form. In addition, where rice is eaten as a staple, it is possible to ensure regular intake. In the present study, we showed that boiled $A \beta$ rice does not reduce the efficacy of the vaccine, thereby allowing its use as an edible vaccine. The ease of use of an $A \beta$ rice vaccine for AD makes this the most attractive vaccine for preventing and treating the disease.

\section{Acknowledgements}

We would like to thank Dr. S. Hidaka and Dr. N. Yamagishi for valuable advice. This work was supported in part by funding for Research for Promoting Technological Seeds from the Japan Science and Technology Agency.

\section{Conflict of interests}

The authors have declared that no conflict of interest exists.

\section{References}

1. Selkoe DJ. Alzheimer's disease: a central role for amyloid. J Neuropathol Exp Neurol. 1994; 53: 438-447.

2. Carlson GA. A welcoming environment for amyloid plaques. Nat Neurosci. 2003; 6: 328-330.

3. Schenk D, Barbour R, Dunn W, et al. Immunization with amyloid- $\beta$ attenuates Alzheimer-disease-like pathology in the PDAPP mouse. Nature 1999; 400: 173-177.

4. Bard F, Cannon C, Barbour R, et al. Peripherally administered antibodies against amyloid $\beta$-peptide enter the central nervous system and reduce pathology in a mouse model of Alzheimer disease. Nat Med. 2000; 6: 916-919.

5. Weiner HL, Lemere CA, Maron R, et al. Nasal administration of amyloid- $\beta$ peptide decreases cerebral amyloid burden in a 
mouse model of Alzheimer's disease. Ann Neurol. 2000; 48: 567-579.

6. Janus C, Pearson J, McLaurin J, et al. A $\beta$ peptide immunization reduces behavioural impairment and plaques in a model of Alzheimer's disease. Nature 2000; 408: 979-982.

7. Morgan D, Diamond DM, Gottschall PE, et al. A $\beta$ peptide vaccination prevents memory loss in an animal model of Alzheimer's disease. Nature 2000; 408: 982-985.

8. Check E. Nerve inflammation halts trial for Alzheimer's drug. Nature 2002; 415: 462.

9. Holmes C, Boche D, Wilkinson D, et al. Long-term effects of A 342 immunisation in Alzheimer's disease: follow-up of a randomised, placebo-controlled phase I trial. Lancet 2008; 372: 216-223.

10. Kim HD, Cao Y, Kong K, et al. Induction of a Th2 immune response by co-administration of recombinant adenovirus vectors encoding amyloid $\beta$-protein and GM-CSF. Vaccine 2005; 23: 2977-2986.

11. Ishii-Katsuno R, Nakajima A, Katsuno $T$, et al. Reduction of amyloid $\beta$-peptide accumulation in Tg2576 transgenic mice by oral vaccination. Biochem Biophys Res Commun. 2010; 399: 593-599.

12. Szabó B, Hori K, Nakajima A, et al. Expression of amyloid- $\beta$ 1-40 and 1-42 peptides in Capsicum annum var. angulosum for oral immunization. Assay Drug Dev Technol. 2004; 2: 383-388.

13. Kim HS, Euym JW, Kim MS, et al. Expression of human $\beta$-amyloid peptide in transgenic potato. Plant Sci. 2003; 165: 1445-1451.

14. Youm JW, Kim H, Han JH, et al. Transgenic potato expressing $A \beta$ reduce $A \beta$ burden in Alzheimer's disease mouse model. FEBS Lett. 2005; 579: 6737-6744.

15. Chu CC, Wang CC, Sun CS, et al. Establishment of an efficient medium for another culture of rice through comparative experiments on the nitrogen sources. Sci Sin. 1975; 18: 659-668.

16. Toki S, Hara N, Ono K, et al. Early infection of scutellum tissue with Agrobacterium allows high-speed transformation of rice. Plant J. 2006; 47: 969-976.

17. Niwa $Y$, Hirano T, Yoshimoto $K$, et al. Non-invasive quantitative detection and applications of non-toxic, S65T-type green fluorescent protein in living plants. Plant J. 1999; 18: 455-463.

18. Ohta $S$, Mita $S$, Hattori $T$, et al. Construction and expression in tobacco of a $\beta$-glucuronidase (GUS) reporter gene containing an intron within the coding sequence. Plant Cell Physiol. 1990; 31: 805-813.

19. Hiei Y, Ohta S., Komari T, et al. Efficient transformation of rice (Oryza sativa L.) mediated by Agrobacterium and sequence analysis of the boundaries of the T-DNA. Plant J. 1994; 6: 271-282.

20. Rashid H, Yokoi S, Toriyama K, et al. Transgenic plant production mediated by Agrobacterium in Indica rice. Plant Cell Rep. 1996; 15: 727-730.

21. Sigurdsson EM, Knudsen E, Asuni A, et al. An attenuated immune response is sufficient to enhance cognition in an Alzheimer's disease mouse model immunized with amyloid-beta derivatives. J Neurosci. 2004; 24: 6277-6282.

22. Pickering RJ, Smith SD Strugnell RA, et al. Crude saponins improve the immune response to an oral plant-made measles vaccine. Vaccine 2006; 24: 144-150. 